\title{
Determination of Molecular Weight of Poly(methyl methacrylate) by Deuterium NMR and Its Reliability
}

\author{
Koichi Hatada, Koichi Ute, and Masaharu KashiYama \\ Department of Chemistry, Faculty of Enginnering Science, Osaka University, \\ Toyonaka, Osaka 560, Japan
}

(Received February 3, 1990)

\begin{abstract}
The number average molecular weight $M_{n}$ of the PMMA prepared by the living polymerization with $\mathrm{CH}_{3}\left(\mathrm{CD}_{3}\right)_{2} \mathrm{CMgBr}$ was determined by the absolute method using deuterium NMR. The $M_{n}$ value agreed well with that determined by proton NMR, based on the intensity ratio of the signal due to the methoxy group in monomeric units to the signal due to the $\mathrm{CH}_{3}\left(\mathrm{CD}_{3}\right)_{2} \mathrm{C}$ - group at the left (initiating) end of chain. The results showed that $\mathrm{Mn}$ up to $10^{5}$ can be determined reliably by deuterium NMR spectroscopy, when the experimental conditions are carefully arranged.
\end{abstract}

KEY WORDS Deuterium NMR / End-group Analysis / Molecular Weight / Poly(methyl methacrylate) / $t$-Butylmagnesium Bromide / Anionic Polymerization / Living Polymerization /

Several papers have been published on the application of dueterium $\left({ }^{2} \mathrm{H}\right)$ NMR spectroscopy to the analysis of the end-groups in polymers. $^{1-4}$ As already reported, ${ }^{1,2}$ endgroup analysis by this technique offers some general advantages: (1) studies of the endgroups by NMR methods is more informative than those by radioactive techniques because they lead to understanding not only of the contents of the groups but also their structures, (2) the preparation of ${ }^{2} \mathrm{H}$-labelled initiators such as 2,2'-azobisisobutyronitrile- $d_{12}$ (AIBN$d_{12}$ ) is easier and/or less expensive than that of initiators enriched with other isotope such as ${ }^{3} \mathrm{H},{ }^{13} \mathrm{C},{ }^{14} \mathrm{C}$, or ${ }^{15} \mathrm{~N}$, and also than the preparation of totally deuterated monomers, ${ }^{5-7}$ (3) the natural abundance of deuterium is so little that the NMR signals for ${ }^{2} \mathrm{H}$-enriched groups in a polymer are hardly affected by the "background" signals, due to the remainder of the polymer molecule.

Bevington and his coworkers ${ }^{1,2}$ observed the ${ }^{2} \mathrm{H}$ NMR signals due to the initiator fragments in the copolymers prepared by the polymeriza- tion initiated with AIBN- $d_{12}$, although the authors were not concerned with intensity measurement of the signals. Hatada et al. ${ }^{3}$ polymerized styrene with AIBN- $d_{12}$ and determined the content of the initiator fragments incorporated in the polymer chain by ${ }^{2} \mathrm{H}$ NMR; the polystyrene was found to contain $1.65\left(\mathrm{CD}_{3}\right)_{2} \mathrm{C}(\mathrm{CN})$ - fragments per chain, which was consistent with the results of ${ }^{1} \mathrm{H}$ NMR analysis of the poly(styrene- $d_{8}$ ) prepared with undeuterated AIBN (1.59). The quantitative use of ${ }^{2} \mathrm{H}$ NMR spectroscopy in the determination of the degree of polymerization was also demonstrated for oligosaccharides. $^{8}$

In the present work, the accuracy of endgroup assay using ${ }^{2} \mathrm{H}$ NMR has been examined through the analysis of the poly(methyl methacrylate) (PMMA) carrying exactly one $\mathrm{CH}_{3}\left(\mathrm{CD}_{3}\right)_{2} \mathrm{C}$ - group per chain. The PMMA was prepared by the living polymerization ${ }^{9,10}$ in toluene at $-78^{\circ} \mathrm{C}$ initiated with $t$-butylmagnesium- $d_{6}$ bromide and terminated with methanol- $d_{4}$ : 
<smiles>COC(=O)C(C)=CBr</smiles><smiles>[2H]C(C)C(C)C(=O)OC</smiles>

Since the PMMA has exactly one $\mathrm{CH}_{3}\left(\mathrm{CD}_{3}\right)_{2}$ C- group per chain, ${ }^{9,10}$ we can evaluate the number average molecular weight $M_{n}$ of the PMMA by ${ }^{2} \mathrm{H}$ NMR measurement from the equation $M_{n}=6 d c / s r$, where $d$ is the isotopic purity $\left({ }^{2} \mathrm{H}\right)$ for the $\mathrm{CH}_{3}\left(\mathrm{CD}_{3}\right)_{2} \mathrm{C}$ - group, $c$ and $s$ are the concentrations of the polymer sample (g-sample/g-solvent) and of ${ }^{2} \mathrm{H}$ of the nitrobenzene- $d_{5}$ added as an internal standard in the sample solution (gram deuterium/gsolvent), respectively, and $r$ is the relative intensity of the $\mathrm{CH}_{3}\left(\mathrm{CD}_{3}\right)_{2} \mathrm{C}$ - resonance to the standard.

The principal feature of the present technique is that the degree of polymerization $D P$ of the identical sample can be determined also by means of ${ }^{1} \mathrm{H}$ NMR spectroscopy, from the intensity ratio of the ${ }^{1} \mathrm{H}$ signals due to the $\mathrm{CH}_{3}\left(\mathrm{CD}_{3}\right)_{2} \mathrm{C}$ - and the $\mathrm{CH}_{3} \mathrm{O}$ - groups. $M_{n}$ of the PMMA is then given by $(100.1 \times D P)$ +65.1 , where the values 100.1 and 65.1 are the formula weight of the monomeric unit $\left(\mathrm{C}_{5} \mathrm{H}_{8} \mathrm{O}_{2}\right)$ and that of end-groups $\left(\mathrm{C}_{4} \mathrm{D}_{6} \mathrm{H}_{3}+\right.$ D), respectively. The $D P$ value needs to be corrected for the isotopic purity of the $\mathrm{CH}_{3}$ $\left(\mathrm{CD}_{3}\right)_{2} \mathrm{C}$ - group. Reliability of the intensity measurement by ${ }^{1} \mathrm{H}$ NMR is well established. ${ }^{11}$

\section{EXPERIMENTAL}

$t$-Butylmagnesium- $d_{6}$ bromide was prepared from $t$-butyl- $d_{6}$ bromide $(21 \mathrm{mmol})$ and magnesium $(31 \mathrm{mmol})$ in diethyl ether under dry nitrogen atmosphere. Concentrations of $\mathrm{Mg}^{2+}$ and $\mathrm{CH}_{3}\left(\mathrm{CD}_{3}\right)_{2} \mathrm{CMg}-$ in the solution were determined as $0.712 \mathrm{M}$ by chelatometric titration, and $0.265 \mathrm{M}$ by acid-base titration, respectively $\left(\left[\mathrm{Mg}^{2+}\right] /\left[\mathrm{CH}_{3}\left(\mathrm{CD}_{3}\right)_{2} \mathrm{CMg}-\right]=\right.$ 2.69). $t$-Butyl- $d_{6}$ bromide was synthesized in $84 \%$ yield from phosphorus tribromide and $t$-butanol- $d_{6}$ which was prepared from acetone$d_{6}$ (Aldrich) and methylmagnesium bromide. Isotopic purity of the $t$-butyl- $d_{6}$ bromide was determined as $98.20 \%$ by mass spectroscopic analysis, thus the average composition of ${ }^{1} \mathrm{H}$ and ${ }^{2} \mathrm{H}$ nuclei in the $t$-butyl- $d_{6}$ group was $3.108: 5.892$.

Polymerization of MMA with $t$-butylmagnesium- $d_{6}$ bromide in toluene at $-78^{\circ} \mathrm{C}$ was conducted in a procedure similar to that with $t$-butylmagnesium bromide. ${ }^{9,10}$ The polymerization was terminated by adding a small amount of methanol- $d_{4}$ to the polymerization mixture, and the mixture was poured into $300 \mathrm{ml}$ of hexane. The precipitated polymer was recovered by filtration, and was freeze dried with benzene. The yield of the polymer was quantitative.

${ }^{1} \mathrm{H}$ NMR spectrum was measured on a JEOL JNM-GX500 spectrometer in nitrobenzene- $d_{5}$ solution at $110^{\circ} \mathrm{C} ; 16$ scans were accumulated with a repetition time of $15 \mathrm{~s}$, using a $90^{\circ}$ observation pulse. ${ }^{2} \mathrm{H}$ NMR spectrum was recorded on a JEOL JNM-GSX400 spectrometer with a $10 \mathrm{~mm}$ multinuclear probe operated at $61.3 \mathrm{MHz}$ and $110^{\circ} \mathrm{C}$. Nitrobenzene containing a certain amount of nitrobenzene- $d_{5}$ (isotopic purity $99.55 \%$ ) was employed as solvent. The concentration of ${ }^{2} \mathrm{H}$ in the solvent ( $s$ ) was determined as $s=5 d f / \mathrm{MW}$ $\left(\mathrm{C}_{6} \mathrm{D}_{5} \mathrm{NO}_{2}\right)$, where $d$ is the isotopic purity of the nitrobenzene- $d_{5}, f$ is the weight fraction of nitrobenzene- $d_{5}$ in the solvent and $\mathrm{MW}$ $\left(\mathrm{C}_{6} \mathrm{D}_{5} \mathrm{NO}_{2}\right)$ is the formula weight for $\mathrm{C}_{6} \mathrm{D}_{5}$ $\mathrm{NO}_{2}=128.15$. The magnetic field was internally-locked by the ${ }^{2} \mathrm{H}$ resonance due to nitrobenzene- $d_{5}$ and was shimmed by monitoring the resonance, then the field-lock was off just before the ${ }^{2} \mathrm{H}$ NMR measurement. The NMR data consisted of $8 \mathrm{~K}$ data points covering $1227 \mathrm{~Hz}$, and 64 scans were accumulated with a repetition time of $5.0 \mathrm{~s}$ using a $90^{\circ}$ 
$(40.0 \mu \mathrm{s})$ pulse. A line-broadening factor of $0.15 \mathrm{~Hz}$ was applied. Chemical shift for the ${ }^{1} \mathrm{H}$ and ${ }^{2} \mathrm{H}$ NMR spectra referred to the signal due

Table I. ${ }^{1} \mathrm{H}$ and ${ }^{2} \mathrm{H}-T_{1}$ values measured at $110^{\circ} \mathrm{C}$ for the PMMA prepared with $\mathrm{CH}_{3}\left(\mathrm{CD}_{3}\right)_{2} \mathrm{CMgBr}$ in toluene ${ }^{\mathrm{a}}$

\begin{tabular}{|c|c|c|}
\hline & \multicolumn{2}{|c|}{$T_{1} / \mathrm{s}$} \\
\hline & $\begin{array}{c}{ }^{1} \mathrm{H} \\
500 \mathrm{MHz}\end{array}$ & $\begin{array}{c}{ }^{2} \mathrm{H} \\
61.3 \mathrm{MHz}\end{array}$ \\
\hline $\mathrm{CH}_{3}\left(\mathrm{CD}_{3}\right)_{2} \mathrm{C}-$ & 1.376 & 0.173 \\
\hline PMMA $\left\{\begin{array}{l}\mathrm{CH}_{3}^{-} \\
\mathrm{CH}_{3} \mathrm{O}_{-}^{-}\end{array}\right.$ & $\begin{array}{r}0.409 \\
1.104 \\
12.37^{\mathrm{b}}\end{array}$ & $\overline{-}$ \\
\hline $\mathrm{C}_{6} \mathrm{D}_{5} \mathrm{NO}_{2}\left\{\begin{array}{l}m- \\
p-\end{array}\right.$ & $\begin{array}{l}12.61^{\mathrm{b}} \\
12.43^{\mathrm{b}}\end{array}$ & $\begin{array}{l}0.815 \\
0.559\end{array}$ \\
\hline
\end{tabular}

a The sample PMMA-6K in Table III was used.

b $T_{1}$ of the residual proton. to meta- ${ }^{1} \mathrm{H}$ (residual) and meta $^{-2} \mathrm{H}$ of nitrobenzene- $d_{5}$ as $7.352 \mathrm{ppm}$, respectively. Intensities of the ${ }^{1} \mathrm{H}$ and ${ }^{2} \mathrm{H}$ resonances were measured by digital integration. Spin-lattice relaxation time $\left(T_{1}\right)$ was determined by the inversion-recovery method (Table I). The values confirm that the repetition time in the ${ }^{1} \mathrm{H}$ and ${ }^{2} \mathrm{H}$ NMR measurements exceeds five times $T_{1}$ of any relevant signal.

Mass spectra were recorded on a JEOL JMS-DX303HF spectrometer.

\section{RESULTS AND DISCUSSION}

Three PMMA samples PMMA-6K, PMMA13K and PMMA-23K were prepared by the living polymerization initiated with $t$-butylmagnesium- $d_{6}$ bromide in toluene at $-78^{\circ} \mathrm{C}$. All these samples are highly isotactic $(\mathrm{mm}>$
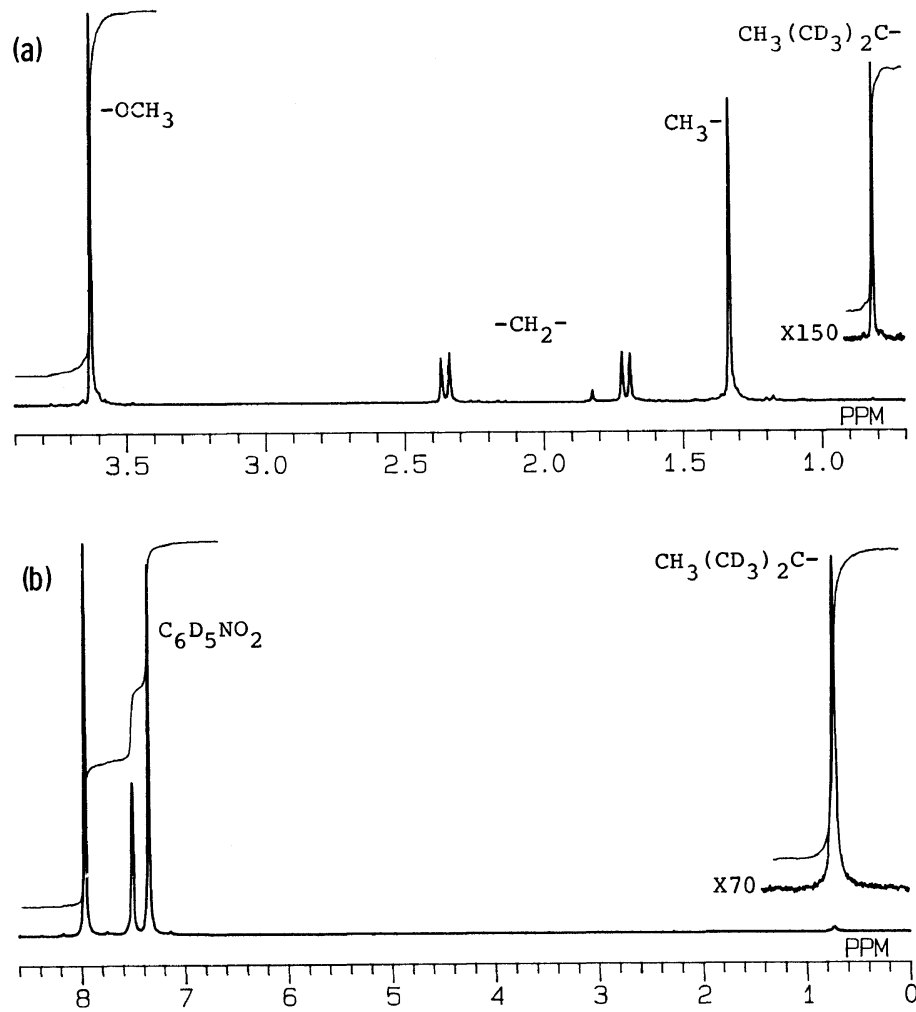

Figure 1. ${ }^{1} \mathrm{H}$ and ${ }^{2} \mathrm{H}$ NMR spectra of the PMMA (PMMA-23K) prepared with $t$-butylmagnesium- $d_{6}$ bromide in toluene at $-78^{\circ} \mathrm{C}$. (a) $500 \mathrm{MHz}{ }^{1} \mathrm{H}$ NMR spectrum measured in nitrobenzene- $d_{5}$ at $110^{\circ} \mathrm{C}$; (b) $61.3 \mathrm{MHz}{ }^{2} \mathrm{H}$ NMR spectrum measured in nitrobenzene/nitrobenzene- $d_{5}(95 / 5)$ at $110^{\circ} \mathrm{C}$. 
Table II. Concentrations of the PMMA prepared with $\mathrm{CH}_{3}\left(\mathrm{CD}_{3}\right)_{2} \mathrm{CMgBr}(c)$ and of ${ }^{2} \mathrm{H}$ of $\mathrm{C}_{6} \mathrm{D}_{5} \mathrm{NO}_{2}(s)$ in the sample solution and the relative intensity $(r)$ of the ${ }^{2} \mathrm{H}$ NMR signals

\begin{tabular}{ccccc}
\hline \multirow{2}{*}{ Sample } & \multicolumn{1}{c}{$c^{\mathrm{a}}$} & \multicolumn{2}{c}{$s^{\mathbf{b}}$} & \multicolumn{2}{c}{$\sigma(r)^{\mathrm{c}}$} \\
\cline { 2 - 3 } & $\mathrm{g} / \mathrm{g}$ & $\mathrm{gram}-{ }^{2} \mathrm{H} / \mathrm{g}$ & & 0.00038 \\
\hline PMMA-6K & 0.10327 & 0.002001 & 0.04613 & 0.00025 \\
PMMA-13K & 0.10066 & 0.001943 & 0.02331 & 0.00034 \\
PMMA-23K & 0.09684 & 0.001929 & 0.01238 & \\
\hline
\end{tabular}

a $c=\mathrm{wt}(\mathrm{PMMA}) /\left(\mathrm{wt}\left(\mathrm{C}_{6} \mathrm{H}_{5} \mathrm{NO}_{2}\right)+\mathrm{wt}\left(\mathrm{C}_{6} \mathrm{D}_{5} \mathrm{NO}_{2}\right)\right)$

b $s=5 d f / \mathrm{MW}\left(\mathrm{C}_{6} \mathrm{D}_{5} \mathrm{NO}_{2}\right) ; d=0.9955$ (isotopic purity of $\left.\mathrm{C}_{6} \mathrm{D}_{5} \mathrm{NO}_{2}\right) ; f=w t\left(\mathrm{C}_{6} \mathrm{D}_{5} \mathrm{NO}_{2}\right) /\left(w \mathrm{wt}\left(\mathrm{C}_{6} \mathrm{H}_{5} \mathrm{NO}_{2}\right)+\mathrm{wt}\left(\mathrm{C}_{6} \mathrm{D}_{5}\right.\right.$ $\left.\mathrm{NO}_{2}\right)$ ); $\mathrm{MW}\left(\mathrm{C}_{6} \mathrm{D}_{5} \mathrm{NO}_{2}\right)=128.15$.

c Estimated standard deviations:

$$
\sigma(r)=\left[\Sigma\left(r_{i}-r\right)^{2} /(n-1)\right]^{1 / 2}, \quad n=5 .
$$

$97 \%$ ) and have a narrow molecular weight distribution $\left(M_{w} / M_{n}<1.20\right)$.

Figure 1a shows the $500 \mathrm{MHz}{ }^{1} \mathrm{H}$ NMR spectrum of PMMA-23K (see Table III) measured in nitrobenzene- $d_{5}$ at $110^{\circ} \mathrm{C}$. The signal at $3.636 \mathrm{ppm}$ is assigned to the $\mathrm{CH}_{3} \mathrm{O}$ - group in the monomeric units and the signal at $0.823 \mathrm{ppm}$ to the $\mathrm{CH}_{3}\left(\mathrm{CD}_{3}\right)_{2} \mathrm{C}$ group at the left (initiating) end of the chain. The intensity ratio of these two signals was determined as 220.5. This value was corrected for the isotopic purity of the $\mathrm{CH}_{3}\left(\mathrm{CD}_{3}\right)_{2} \mathrm{C}$ group to give the DP of this PMMA (228.4). Thus $M_{n}$ of the polymer was calculated to be $22.93 \times 10^{3}$ on the basis of the formula weights of the monomeric unit and the terminal groups. $M_{n}$ 's of PMMA-6K and PMMA-13K were determined by ${ }^{1} \mathrm{H}$ NMR in a similar manner (see Table III).

${ }^{2} \mathrm{H}$ NMR spectra of the PMMA samples were measured in nitrobenzene containing a certain amount of nitrobenzene- $d_{5}$ as an intensity standard. Table II gives the concentrations of the PMMA (c) and of ${ }^{2} \mathrm{H}$ of nitrobenzene- $d_{5}(s)$ in sample solutions. Figure $1 \mathrm{~b}$ shows the $61.3 \mathrm{MHz}{ }^{2} \mathrm{H}$ NMR spectrum of PMMA-23K. The ${ }^{2} \mathrm{H}$-nuclei in the $\mathrm{CH}_{3}$ $\left(\mathrm{CD}_{3}\right)_{2} \mathrm{C}$ - group resonates at $0.735 \mathrm{ppm}$; the chemical shift value is $0.088 \mathrm{ppm}$ smaller than that of the ${ }^{1} \mathrm{H}$-nuclei in the $\mathrm{CH}_{3}\left(\mathrm{CD}_{3}\right)_{2} \mathrm{C}$ group. The relative intensity $(r)$ of the signal
Table III. The number average molecular weight $M_{n}$ of the PMMA samples determined by VPO, ${ }^{1} \mathrm{H}$ NMR and ${ }^{2} \mathrm{H}$ NMR

\begin{tabular}{crcr}
\hline \multirow{3}{*}{ Sample } & \multicolumn{3}{c}{$M_{n} / 10^{3}$} \\
\cline { 2 - 4 } & \multicolumn{1}{c}{ VPO } & ${ }^{1}$ H NMR & ${ }^{2}$ H NMR \\
\hline PMMA-6K & 6.17 & 6.80 & 6.47 \\
PMMA-13K & 12.49 & 13.21 & 12.84 \\
PMMA-23K & 22.28 & 22.93 & 23.89 \\
\hline
\end{tabular}

due to the $\mathrm{CH}_{3}\left(\mathrm{CD}_{3}\right)_{2} \mathrm{C}-$ group to the standard signal due to nitrobenzene- $d_{5}$ (7.3$8.0 \mathrm{ppm}$ ) was determined as 0.01929 (Table II). The ${ }^{2} \mathrm{H}$ NMR measurement was conducted five times for each sample, and the estimated standard deviation $\sigma(r)$ was within $3 \%$ of the mean value in all the cases. $M_{\mathrm{n}}$ 's of the PMMA samples were calculated as $M_{n}=6 d c / s r$.

Table III summarizes the results of the $M_{n}$ measurements by VPO, ${ }^{1} \mathrm{H}$ NMR and ${ }^{2} \mathrm{H}$ NMR. The $M_{n}$ values determined by ${ }^{1} \mathrm{H}$ and ${ }^{2} \mathrm{H}$ NMR are in good agreement with each other. The $M_{n}$ values determined by VPO were about $5 \%$ lower than the values by ${ }^{1} \mathrm{H}$ and ${ }^{2} \mathrm{H}$ NMR. However, the formation of the PMMA without $\mathrm{CH}_{3}\left(\mathrm{CD}_{3}\right)_{2} \mathrm{C}$ - group at the left end of chain seems to be unlikely. The reason is presently unknown. Considering the signal-tonoise ratio of the ${ }^{2} \mathrm{H}$ NMR spectrum of PMMA-23K (Figure 2b), little difficulty is 
expected in the determination of $M_{n}$ up to $10^{5}$ by this method. The results mentioned here clearly indicate the good accuracy and good sensitivity of the end-group analysis of polymer by ${ }^{2} \mathrm{H}$ NMR spectroscopy, when the experimental conditions are carefully arranged.

Acknowledgments. The authors are grateful to Mrs. F. Yano for her VPO measurement. A part of this work was supported by a Grant-in-Aid for Scientific Research (No. 61430022) from the Ministry of Education, Science, and Culture of Japan.

\section{REFERENCES}

1. J. C. Bevington, T. N. Huckerby, and N. W. E.
Hutton, Eur. Polym. J., 18, 963 (1982).

2. J. C. Bevington, T. N. Huckerby, and N. W. E. Hutton, Eur. Polym. J., 20, 525 (1984).

3. K. Hatada, T. Kitayama, and E. Masuda, Polym. J., 17, 985 (1985).

4. K. Ute, Y. Tashima, T. Saito, and K. Hatada, Polym. Prepr. Jpn., 38, 134; E34 (1989).

5. K. Hatada, T. Kitayama, K. Fujikawa, K. Ohta, and H. Yuki, ACS Symp. Ser., 166, 327 (1981).

6. K. Hatada, T. Kitayama, S. Okahata, and H. Yuki, Polym. J., 13, 1045 (1981).

7. K. Ute, T. Kitayama, and K. Hatada, Polym. J., 18, 249 (1986).

8. W. J. Goux, Carbohydr. Res., 173, 293 (1988).

9. K. Hatada, K. Ute, K. Tanaka, T. Kitayama, and Y. Okamoto, Polym. J., 17, 977 (1985).

10. K. Hatada, K. Ute, K. Tanaka, Y. Okamoto, and T. Kitayama, Polym. J., 18, 1037 (1986).

11. R. Chûjô, K. Hatada, R. Kitamaru, T. Kitayama, H. Sato, Y. Tanaka, Polym. J., 19, 413 (1987). 